\title{
The perfect smile - Part 2
}

\section{By Rose Xi Man Poon, University of Dundee}

Rose Xi Man Poon, a final year dental student from University of Dundee and fellow students Ai Tan, Thean Wei Yap, Christy Ng, Jonathan Lewis, Ciara Rocks, and Erin Macaskill continue a series of articles on the topic of 'The Perfect Smile', looking at the perception of different perfect smiles around the world.

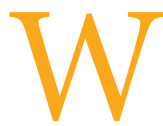
hat makes the perfect smile? The answer to this question depends on your own idea of perfection, and can be defined differently around the world. However, in this day and age, dentistry is playing a larger role in people's lives and as a consequence there is greater desire to achieve the 'perfect smile'.

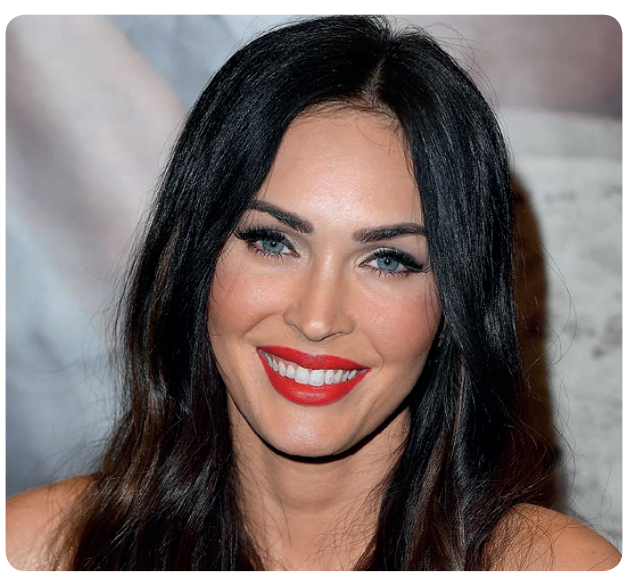

Megan Fox

AMERICA: The Famous Hollywood Smile Simon Cowell, Megan Fox, Tom Cruise, Morgan Freeman, George Clooney - it is not difficult to identify an American celebrity on TV, as they all have the flawless Hollywood smile.

The Americans are known to be obsessed with straight and pearly white teeth. According to a survey, approximately 39 million Americans - around 12\% of the population - used teeth whiteners. In the USA, cosmetic dentistry is the largest non-surgical beauty industry after makeup. Their perception towards the 'perfect' smile is greatly influenced by their history.

During the time of the Great Depression, dentist Charles Pincus opened his practice in Hollywood and Vine. He then began advertising to the movie studios. Veneers were used to cover up teeth imperfections and created great smiles for famous actors like James Dean, Judy Garland and Shirley Temple to match their symmetrical faces.

Since then, a symmetrical and aesthetically pleasing smile has become associated with wealth and fame. Americans believe having a Hollywood smile can boost self-esteem and give a better first impression.

Men and women with prominent, chiselled jaws are thought to be more attractive as a strong jawline helps to evoke a confident and powerful look. Chin implants, neck lifts, cheek fat pad removals, BOTOX cosmetic injections are common procedures people do to create a sleek profile to the face. Thick lips are also a desirable feature as they can enhance the smile by hiding discrepancies. Lip augmentation using BOTOX or filler is a popular choice of treatment.

Healthy looking gum is another contributing factor to achieve the American's perception of a perfect smile. It should be bright pink in colour, and follow the contour of the teeth. Minimal gum exposure is favoured.

Flashing a smile with grills on can make your smile worth slightly less than a million dollars. Literally. Gold grills, which are gold

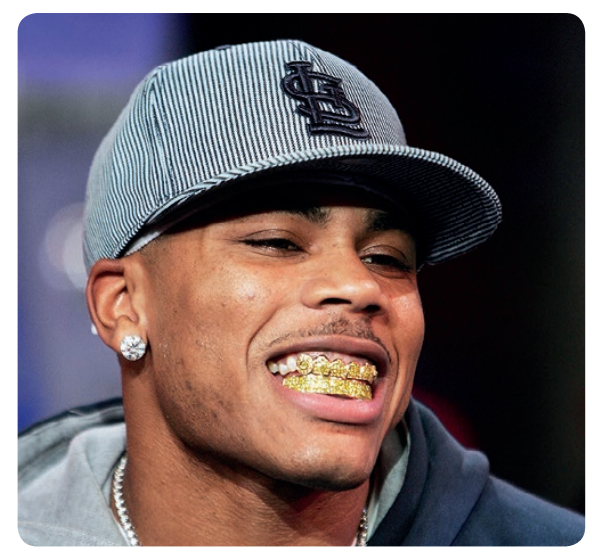

Nelly with his gold mould, diamond studded grills which reportedly cost more than $\$ 100,000$

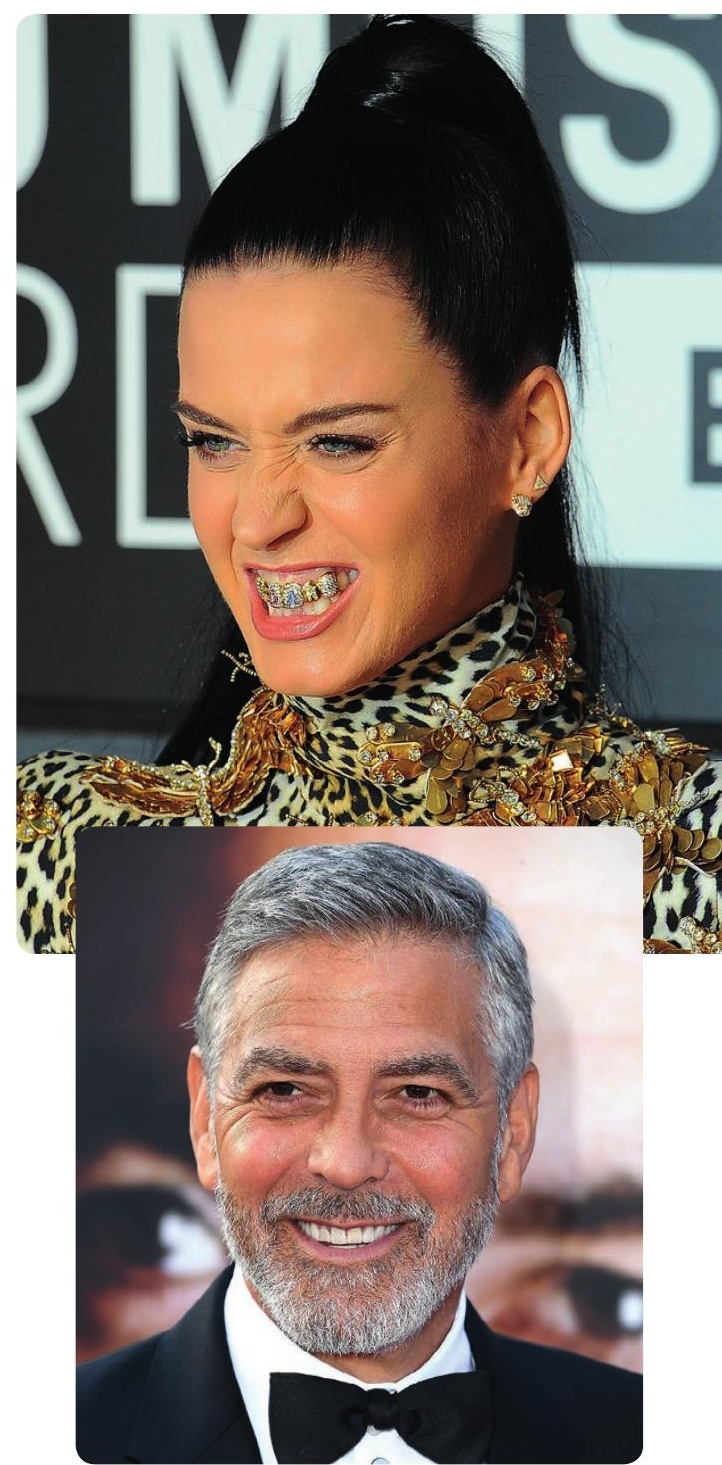

Top: Katy Perry showing off her grills

Bottom: George Clooney

false teeth covers, became a trend among hip hop artists in the 1980s.

It is said that Eddie Plein (the owner of Eddie's Gold Teeth) first brought the trend to New York. He outfitted Slick Rick with gold caps as well as rappers like Big Daddy Kane and Kool G Rap.

When he moved to Atlanta, he designed more elaborate and expensive grills for artists such as Ludacris and Lil Jon. Grills were mainstreamed by Nelly with his song 'Grillz' and celebrities such as Beyoncé, and even white artists like Miley Cyrus and Madonna, have jumped on the bandwagon.

Some grills are inlaid with precious stones which further emphasised that grills were a look for the rich and famous. It is understood that artists like Lil Wayne and Kanye West paid more than $\$ 100,000$ for grills. However, if you fancy a cheaper option you can get grills as cheap as $\$ 20$ made of stainless steel. 